\title{
RETENÇÃO SINTÁTICA \\ NO PORTUGUÊS DO BRASIL: \\ ANÁLISE DE UM FENÔMENO
}

Heloísa Maria Moraes Moreira Penna Universidade Federal de Minas Gerais

\section{Introdução}

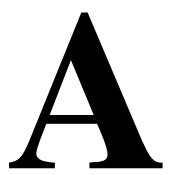

língua portuguesa contemporânea falada no Brasil, como atestam diversos estudos, já se distanciou da mesma língua falada hoje em Portugal. As causas do distanciamento dos dois sistemas, o português de Portugal e o português do Brasil, estão, em grande parte, relacionadas, pelos gramáticos, às mudanças sofridas pelo português aqui no Brasil. Entre estas estão as que denominam de brasileirismos, ou seja, modos de falar peculiares ao povo brasileiro. São inúmeros os fatos lingüísticos rotulados de brasileirismos nos manuais de Língua Portuguesa. Porém, num estudo mais recuado da história da língua percebe-se que, sob essa classificação, estão muitos fenômenos lingüísticos que não representam de fato criação do povo brasileiro, mas sim conservação de estruturas lingüísticas já há muito "perdidas" no país português d'além-mar. Essa permanência de elementos arcaicos no português brasileiro contribuiu, do mesmo modo que as inovações, para a diferenciação dos dois sistemas.

O presente $\operatorname{artigo}^{1}$ tem o objetivo de focalizar um desses fenômenos de retenção de estruturas que mostra que a língua

\footnotetext{
${ }^{1}$ Este artigo baseia-se na dissertação de mestrado Oemprego do pronome tônico de terceira pessoa em função acusativa no português do Brasil: mudança ou retenção? Apresentada em julho de 1998, na Faculdade de Letras da UFMG, sob a orientação da professora Dra. Maria Antonieta de Amarante Cohen.
} 
portuguesa falada hoje no Brasil, em certos aspectos, se aproxima da língua portuguesa trazida pelos primeiros colonizadores e, ao mesmo tempo, se distancia, por este mesmo cunho conservador, do português europeu atual.

\section{O fenômeno em questão}

O fenômeno aqui focalizado é o emprego do pronome tônico de $3^{\underline{a}}$ pessoa em função objetiva direta, doravante ele acusativo, no português brasileiro contemporâneo sob uma perspectiva diacrônica.

A prática do emprego do pronome de terceira pessoa como objeto direto, no dia a dia, no português do Brasil, mostra-se contrário às prescrições das gramáticas normativas: o que se observa é o uso do pronome lexical ele e suas flexões em função acusativa, na língua oral e escrita formal e informal. Em contrapartida, o emprego das formas oblíquas "está associado a aprendizado escolar, revela grau de instrução elevado e é identificado com língua escrita e estilo formal."

Exemplos como os seguintes, extraídos de programas de televisão, comprovam esse fato:

(1) Eu procurava ele de madrugada para conversar. (TV, 1997)

(2) Eu chamei ela amigavelmente e falei pra ela. (TV, 1997)

(3) Eles não falam português mas pode entrevistar eles. (TV, 1997)

Fenômeno como o representado de (1) a (3) pode ser encontrado também no português do período arcaico:

(4) Damos elle a uos e a toda uossa uoz. (Notarial, XIV)

(5) ...e as justiças não agrauen eles cõtra sas forças. (Notarial, XIII)

(6) ...aquella uina dos mymẽtos qual foy de Pelayo Fernandes en tal maneyra que lauredes ella. (Notarial, XIII)

${ }^{2}$ NUNES, 1993. p.207. 
Os dados de (1) a (6) apresentam-nos o emprego do pronome tônico de terceira pessoa em função de objeto direto em dois períodos da língua portuguesa.

Diante desse fato propus, para o presente trabalho, dois cortes sincrônicos de períodos separados um do outro por centenas de anos: o período arcaico (XIII ao XVI) e o contemporâneo (XX). Segundo Bynon (1993) há um espaço de tempo ideal de quatro ou cinco séculos que é mais favorável para o estudo da mudança lingüística. Minha pesquisa se insere, portanto, do ponto de vista diacrônico, no quadro dos estudos lingüísticos historicistas que vêm tratando de mudanças e retenções nas línguas, como Bynon (1985, 1993), Leal (1992) e Seabra (1994).

A explicação para a presença do ele acusativo, no período arcaico e no contemporâneo, foi buscada na sua origem latina.

Um estudo detalhado do pronome ele mostrou ser de fundamental importância na explicação dos empregos arcaico e contemporâneo do ele acusativo. A partir do item 6 deste artigo analisamos o conceito de pessoa, o sistema pronominal latino, a evolução dos pronomes demonstrativos do latim ao português, o pronome ille latino e o comportamento do pronome ele em relação aos outros pronomes pessoais do português. Porém, antes de se entrar nesse pequeno estudo morfológico, sintático e semântico do pronome ele e flexões serão apresentados os fatos que nos levaram à referida análise.

\section{A polêmica a respeito da origem do fenômeno: arcaismo ou brasileirismo?}

O registro do emprego do pronome ele como objeto direto em dois períodos do português dividiu os estudiosos em torno do assunto. Seria o emprego do ele acusativo um arcaísmo ou um brasileirismo?

Para os partidários do arcaísmo, o fenômeno, presente no português brasileiro contemporâneo, tem evidente ligação histórica com aquele do período arcaico. Baseiam-se em dados literários arcaicos e dados orais contemporâneos a eles. 
Opondo-se a estes encontra-se um grupo de estudiosos para quem o fato de existirem exemplos deste emprego em época atual e arcaica, não significa obrigatoriamente haver ligação histórica entre os dois. O fenômeno é considerado por eles uma criação brasileira. Referem-se às ocorrências arcaicas como acusativos enfáticos devido à fonte dos dados à sua disposição: as obras literárias.

Pode-se perceber que há entre os partidários do fenômeno como brasileirismo um certo "preconceito" dos dados, até então, registrados. Estes eram extraídos de obras literárias da época arcaica e considerados por eles como enfáticos e esporádicos. Vejamos alguns:

"El rei mandou-o logo prender, e levarem ele a Mateus Fernandes à Sevilha." (Fernão Lopes - D. Fernando - XV apud Silveira Bueno) "El rei de Castela não vinha senão por passar seu caminho, e não por cercar elles nem outros." (Fernão Lopes - D. João I - XV apud Silveira Bueno)

"Mas, assi de longe os ordena eles a ventura..." (Bernadim Ribeiro - Menina e Moça - XVI apud Silveira Bueno)

“...encomendo elas a vos, as quaes vos rogo que sempre ajaes em vossa comenda." (Zurara - XVI)

Dentre os que consideram o fenômeno uma criação brasileira está Mattoso Câmara (1972). O autor considera o pronome ele, no português brasileiro contemporâneo, uma forma sintaticamente invariável exatamente como os nomes e os demonstrativos. Segundo ele, o sistema de pronomes pessoais do português brasileiro contemporâneo passou por mudanças que permitiram a esse pronome ser usado em todas as funções sintáticas, principalmente a de objeto direto, em substituição ao pronome oblíquo $o$.

Maia, ${ }^{3}$ que defende o arcaísmo do fenômeno, diz que a explicação estrutural proposta por Mattoso Câmara ${ }^{4}$ é válida também para o antigo galego português:

${ }^{3}$ MAIA, 1986. p.667.

${ }^{4}$ MATTOSO CÂMARA JR., 1972. 
"já nesse período da língua, ao lado da conservação do sistema casual dos pronomes pessoais (cf., por exemplo eu, me, mim, ele, lhe, o, etc.), podiam as formas tônicas apresentar-se como invariáveis do ponto de vista sintático, desempenhando funções de diversos complementos, quando regidas de preposição, e funções de complemento direto, neste caso sem subordinação a qualquer preposição."

Martins (1994) em sua tese de doutorado "Clíticos na História do Português" apresentou as estruturas em que os pronomes tônicos poderiam aparecer no período arcaico. Ao explorar a documentação arcaica, e especialmente os documentos notariais, a autora chegou à conclusão de que existia, no português medieval e clássico, além da construção reforçativa do tipo "derruba-o a ele" - também chamada de redobro do clítico -, duas outras alternativas:

- uma construção alternativa à citada acima, onde o pronome oblíquo átono e a preposição 'a' caem restando somente um pronome tônico como complemento: "derribarom ele e o cavalo $<$ derribarom-no a ele e ao cavalo; conhece ty mesmo < conhecete a ty mesmo; sobjugam sy mesmos < sobjugam-se a sy mesmos; segure mim e meus portos < segure-me a mim e meus portos.";

- uma construção alternativa àquela em que a posição de objeto direto era ocupada por um clítico acusativo. Essa construção era exclusiva dos pronomes tônicos de terceira pessoa ele, ela, eles, elas: "...e as justiças nõ agrauen eles cõtra sas forças." (Notarial, séc. XIV)

"As duas construções davam origem a frases superficialmente idênticas quando o pronome complemento era uma forma de terceira pessoa (dada a indistinção, neste caso, entre formas retas e oblíquas)". 5

As observações da especialista em textos arcaicos parece nos indicar que os partidários do fenômeno como brasileirismo estão considerando apenas um tipo de construção com pronome tônico acusativo: a considerada enfática (encontrada nos textos literários da época), como existente no português arcaico.

5 MARTINS, 1994. 
Para se evitar a polêmica a respeito da validade dos dados literários arcaicos em comparação com os dados contemporâneos empreendeu-se, nesse estudo, uma busca por registros do fenômeno em outras fontes da época, ou seja, empregos do ele acusativo em documentos não-literários.

\section{A hipótese da substituição}

Os últimos trabalhos que se referiram ao assunto em questão foram produzidos por pesquisadores de orientação variacionista e gerativista. Eles focalizaram, em sua maioria, a queda do clítico acusativo de terceira pessoa e como conseqüência o preenchimento do espaço vazio por pronome tônico, SN's plenos ou categoria vazia. Os 'corpora' coletados variam do século XVIII ao XX. Apenas Omena ${ }^{6}$ coletou dados do período arcaico e atual com o objetivo de fazer um estudo comparativo dos condicionamentos lingüísticos que afetavam a regra de apagamento do pronome oblíquo e favoreciam o uso do pronome sujeito em função de objeto direto.

Os fatores apontados para o progressivo desaparecimento do clítico o e flexões, no português do Brasil, segundo os autores mais recentes são:

- mudança na direção da cliticização fonológica de ênclise para próclise, ocorrida, segundo Nunes (op. cit.) e Cyrino (1993), no século passado;

- enfraquecimento na morfologia de caso (Decat, 1989 e Castilho, 1989);

- classificação do português brasileiro como uma língua de tópico - comentário. (Galves, 1987).

Confirmando a forte presença do fenômeno no português brasileiro contemporâneo alguns desses autores citam estruturas onde o emprego do ele acusativo é considerado correto pelos falantes de

${ }^{6}$ OMENA, 1978. p.101 e ss. 
todas as classes sociais. Nessas construções tornou-se evidente a invariabilidade do pronome ele na função objetiva direta. São elas:

- Em construções de tópico onde este "só pode ser retomado como um dos itens do objeto direto composto por duas formas: o pronome lexical ou o sintagma nominal pleno. Ex.: (1) Meu pai, eu dificilmente vejo ele e minha mãe sem que eles estejam olhando um para o outro."

- "Construções com objeto sentencial preposicionado. Ex.: (13) Uma parou agora porque o marido dela está bem demais. Então o marido proibiu ela de trabalhar.

- Estruturas reduzidas de infinitivo e gerúndio. Ex.: (14) Ontem ele foi ao cardiologista. Eu já deixei ele ir ao cardiologista sozinho há muito tempo.

(15) Quando nós estávamos saindo da loja nós vimos eles quase parando o carro."8

- "Estrutura de objeto direto anafórico de terceira pessoa + numeral só aceita a variante pronome lexical. Ex.: (7) ...o papai e o tio, provavelmente, o Nilson vai buscar eles dois na rodoviária."

Omena ${ }^{10}$ observou, no texto do português arcaico examinado por ela, coincidência de contextos favorecedores do pronome ele acusativo que atuavam também no português brasileiro contemporâneo:

"construções sintáticas bastante semelhantes e repetidas em que invariavelmente ocorria o pronome de caso reto, em função objeto direto. Uma delas era a de objeto direto composto, cujos núcleos apresentavam SNs referentes a um ser humano (primeiro núcleo) e a um ser animado, humano ou não humano (segundo núcleo). Em todos os casos o primeiro SN era um pronome pessoal do caso reto. Ex.: "Entom foi ferir Amatim, o boõ justador, atam bravamente que

7 PONTES, 1987. p.70.

${ }^{8}$ DUARTE, 1989. p.24.

${ }^{9}$ MALVAR, 1992. p.137.

${ }^{10}$ OMENA, 1978. p.116. 
lhe meteu o ferro da lança pelo braço e pelo corpo e meteu ele e o cavalo em terra" Construções que envolviam repetição com reciprocidade e/ou omissão. Ex.: "E Galvom salvou ela e ela a ele." (...) Em todas essas estruturas a constante foi ser o antecedente um ser animado, ou mais precisamente, um ser humano."

\section{Nova fonte para os estudos lingüísticos: os documentos notariais}

O 'corpus' arcaico analisado constituiu-se, principalmente, de documentos notariais portugueses: Notícia de Torto (XIII), Foros e Costumes da Cidade de Évora (XIII), Foros de Castelo Rodrigues (XIII), Notariais do noroeste de Portugal e região de Lisboa (XIII ao XVI) e Notariais da Galiza e noroeste de Portugal (XIII ao XVI). A escolha desse 'corpus' representou uma novidade: os documentos notariais eram poucos pesquisados no estudo de sintaxe histórica. A análise desses documentos arcaicos forneceram ao trabalho não só ocorrências do ele acusativo não enfático mas revelaram, ainda, a forte presença do ele em todas as funções sintáticas, empregos semelhantes aos verificados no português brasileiro contemporâneo:

Ele-sujeito

(1) "E nunca ille fez neu mal por todo aqueste." (Notícia de Torto, XIII)

Ele-objeto direto

(2) "Damos ella a uos que lauredes ella." (Notarial, XIII)

Ele - objeto indireto com ou sem preposição

(3) "...e filo li quanto que li agou e deu a illes." (Notícia de Torto, XIII)

(4) "Se a lexaren intregaren ille de octra que li plaza." (Notícia de Torto, XIII)

Ele - adjunto adnominal

(5) “...enessas ejgreias e os prelados delas des aquel tempo en que foj feito o degredo..." (Notarial, XIV) 
Ele - complemento circunstancial com ou sem preposição

(6) "...que o metesse per ella en posse do dicto mosteiro segundo se en ella cõntjnha." (Notarial, XV)

(7) “...este prazo per ma moo fiz e meu sinal el pusi en testemoyo que tal e." (Notarial, XV)

Com essa "descoberta", ou seja, com um conjunto consistente de dados não literários do período arcaico conseguiram-se duas importantes conquistas para a compreensão do período a que os dados se referem:

- mostrar, contrariamente ao que se acreditava, a existência do ele acusativo sem matiz enfático, nesse período;

- demonstrar a relevância dos documentos notariais para os estudos de sintaxe histórica.

Tornou-se claro que a mesma explicação para a existência dos dados do ele acusativo no período arcaico poderia ser aplicada ao português brasileiro contemporâneo.

Os dados do português brasileiro contemporâneo foram coletados em duas fontes e divididos por duas modalidades, oral e escrita: gravações de programas de televisão (entrevistas, aula de culinária, debates) e textos da escritora mineira Adélia Prado. Ambos tidos como linguagem informal. Algumas ocorrências extraídas de jornal foram coletadas após o término do trabalho de dissertação e se juntam aos dados anteriormente registrados para indicar a "invasão" do fenômeno também na linguagem escrita formal contemporânea. Vejamos alguns dados orais e escritos do ele acusativo no português brasileiro contemporâneo:

(8) Eu procurava ele de madrugada para conversar. (Programa "Márcia" - 1997)

(9) Diz palavrão, você não reconhece ele. (Adélia Prado, 1980)

(10) Forre ela todo com um plástico e cubra um lado... (Estado de Minas - 1999)

Constatou-se, através da análise dos 'corpora' arcaico e contemporâneo, a liberdade sintática do ele, que ocorre nas mais 
variadas funções sintáticas, em ambos os períodos sob análise. Ao lado dessa liberdade sintática, ou por causa dela, notou-se uma preferência pelo emprego da forma tônica ele, regida, em sua maioria, de preposição em detrimento do oblíquo lhe, do possessivo seu e em lugar, ainda, de algumas construções adverbiais.

O quadro abaixo traça um paralelo entre os empregos do ele nos períodos arcaico e contemporâneo da língua portuguesa confirmando a antiguidade do prestígio deste pronome.

\section{Ocorrência do pronome ele no português arcaico em comparação ao português brasileiro contemporâneo}

\section{Quadro I}

\begin{tabular}{|l|c|c|}
\hline \multicolumn{1}{|c|}{ Função Sintática } & $\begin{array}{c}\text { Português } \\
\text { arcaico }\end{array}$ & $\begin{array}{c}\text { Português } \\
\text { contemporâneo }\end{array}$ \\
\hline 1. Sujeito & $\mathrm{X}$ & $\mathrm{X}$ \\
\hline $\begin{array}{l}\text { 2. Objeto direto } \\
\text { ele acusativo } \\
\text { com preposição }\end{array}$ & $\mathrm{X}$ & $\mathrm{X}$ \\
\hline 3. Objeto indireto & $\mathrm{X}$ & \\
Preposição + pronome & $\mathrm{X}$ & $\mathrm{X}$ \\
sem preposição & $\mathrm{X}$ & $\mathrm{X}$ \\
\hline 4. Adjunto adnominal & $\mathrm{X}$ & $\mathrm{X}$ \\
\hline 5. Complemento circunstancial & & $\mathrm{X}$ \\
ele instrumental & $\mathrm{X}$ & $\mathrm{X}$ \\
ele locativo (preposição + ele) & $\mathrm{X}$ & $\mathrm{X}$ \\
ele locativo (sem preposição) & $\mathrm{X}$ & \\
ele com valor reflexivo & & \\
\hline
\end{tabular}

O ele acusativo apareceu, sem matiz enfático, nesses dois períodos da língua portuguesa. Quanto à sua capacidade referencial, os dados mostraram que ele pode referir-se endoforicamente a um elemento do próprio texto ou exoforicamente a um elemento que deve ser recuperado no ambiente extra-textual. 
Dois dialetos portugueses documentaram a existência do ele acusativo no português lusitano contemporâneo: um da região de Algarve e outro da ilha da Madeira.

Diante do resultado exposto acima, a questão básica a ser respondida era: comprovada a existência do fenômeno no período arcaico, o que leva esse pronome a se comportar diferentemente dos outros pronomes pessoais? A resposta parecia estar no conteúdo semântico, morfológico e sintático do pronome ele.

O próximo passo foi voltar ao latim para discutir a origem latina do pronome de terceira pessoa português e buscar, nessa língua, elementos que "justificassem" sua forte presença em todas as funções sintáticas, inclusive, a de objeto direto, no período arcaico e no atual.

Foi importante saber, entre outras coisas, que o chamado pronome de terceira pessoa do português é reconhecidamente uma criação românica a partir de um demonstrativo latino. Essa origem explicou, por exemplo, a maior identidade do ele com os Nomes e Demonstrativos e o seu conseqüente distanciamento dos outros pronomes pessoais.

A próxima seção analisará o pronome ele em seus vários aspectos.

\section{A respeito da origem do pronome de terceira pessoa}

\subsection{Das três pessoas gramaticais}

Ao estabelecermos a origem do que nós classificamos como pronome de terceira pessoa no português e nas outras línguas românicas é necessário que se volte ao latim. O que encontramos nas gramáticas latinas é a expressão formal (pronominal) de apenas duas pessoas: ego, tu (sg.), nos, vos (pl.) no sistema pronominal dessa língua.

A expressão pronominal da chamada terceira pessoa, nas línguas românicas, foi uma criação posterior, considerada pelos romanistas uma inovação românica. 
O sistema pessoal românico composto de três pessoas guarda, também, uma distribuição de noções semânticas e de papéis sintáticos que nos remete ao latim clássico: de um lado a $1^{\underline{a}}$ e $2^{\underline{a}}$ pessoas, de outro a $3^{\underline{a}}$ (sem pronome específico no latim).

Segundo Halliday e Hasan ${ }^{11}$ somente a primeira e a segunda pessoa desempenham os papéis necessários no processo de comunicação. A terceira pessoa não representando nenhum dos dois papéis - o de falante ou o de ouvinte - não pode ser considerada como pessoa.

Daí a ausência de um elemento pronominal para caracterizar a terceira pessoa, como nós a entendemos hoje, no latim e em muitas línguas do passado.

\subsection{Do sistema pronominal latino}

Dos quatro pronomes ille, hic, ipse e is, que em latim se alternavam como sujeitos indicados pela desinência -t, ou como complementos, os dois primeiros eram demonstrativos, ou seja, itens de referência exofórica e endofórica; os outros dois ipse e is eram apenas endofóricos.

Estou seguindo aqui a definição de Halliday e Hasan $^{12}$ segundo a qual existem na língua índices de referência exofórica (textual), cujo elemento referido se identifica no próprio texto, e itens de referência exofórica (situacional), que nos permitem localizar o elemento referido no contexto de situação. Os demonstrativos são itens de referência exofórica e, por extensão, no ambiente textual, podem assumir igualmente valores endofóricos.

Dentre os pronomes latinos citados acima, o ille saiu vitorioso servindo como base, no português, não só para o pronome ele, como também para o artigo o e os demonstrativos aquele e o.

\footnotetext{
${ }^{11}$ HALLIDAY E HASAN, 1976. p.45.

${ }^{12}$ HALLIDAY E HASAN, 1976. p.33.
} 


\subsection{Da evolução dos pronomes demonstrativos}

Os pronomes demonstrativos encerram dupla capacidade referencial - exofórica e endofórica - por serem, primitivamente, itens de referência situacional. Segundo Halliday e Hassan ${ }^{13}$ da referência situacional deriva-se a textual. Esse aspecto semântico mostrou-se o mais relevante para explicar a produtividade do demonstrativo ille, na passagem para as línguas românicas, especialmente sob a forma do pronome pessoal ele.

O processo de evolução dos demonstrativos do latim ao português passou por uma reorganização do sistema pronominal latino devido ao desaparecimento de alguns dos seus elementos. Manteve, entretanto, a distinção dos três pronomes demonstrativos segundo o grau de proximidade com o falante, o ouvinte e com um terceiro elemento referido no discurso.

\subsection{Do pronome ille}

O pronome ille, terceiro no grau de proximidade dos demonstrativos foi o único a não se deslocar de sua posição "que indica um objeto (ou pessoa) longínqua, que não se encontra na proximidade nem da pessoa que fala, nem da pessoa a quem se fala" ${ }^{14}$ na reorganização do sistema pronominal latino. Ele preserva os traços de demonstrativo um pouco modificado, em sua forma, pela anexação de uma partícula de reforço: eccum + ille>aquele.

Desta forma preservou-se o padrão inicial do sistema demonstrativo. A evolução do ille, para o português, resultou em muitas formas e suas funções fóricas originais permaneceram em cada uma delas. Ao mesmo tempo, alcançou-se a simetria formal no quadro dos pronomes pessoais com o seu alinhamento ao lado das outras duas formas pessoais.

\footnotetext{
${ }^{13}$ HALLIDAY e HASAN, op. cit., p.32.

${ }^{14}$ LAUSBERG, 1974. p.346.
} 
As conseqüências formais e funcionais da classificação do ele $(<$ ille) como pronome pessoal, no português, ao lado de eu $(<e g o)$ e $t u(<t u)$ podem ser percebidas quando se procede à comparação interna dos pronomes pessoais. De fato, o ille, como pronome pessoal, nunca chegaria a se igualar semântica e estruturalmente a ego e tu no processo comunicativo. Ele guarda características semânticas da sua origem demonstrativa e características estruturais próprias de um pronome adjetivo, qual seja, flexão de gênero e número.

\subsubsection{Do ille adjetivo latino ao ele substantivo português}

Por sua natureza adjetiva o demonstrativo ille exercia a sua capacidade tipicamente exofórica e secundariamente, dentro do texto, a sua capacidade endofórica. Do emprego adjetivo do ille temse, em português, o artigo definido $o$. Quando substantivado a sua referência típica era endofórica e secundariamente exofórica. As referências exofóricas e endofóricas do pronome ille, então, podem ser associadas ao seu emprego adjetivo ou substantivo. O pronome ele resultou do emprego substantivo do étimo latino e sua referência típica é a endofórica. Pode, ainda, menos comumente, referir-se ao contexto situacional. As flexões pronominais o e the apresentam, também no português, característica endofórica, própria do emprego substantivo do ille. Porém seus empregos como exóforas (referência secundária) são muito mais difíceis de serem registrados.

\subsection{Aspectos morfológicos do pronome ele}

Os aspectos morfológicos do pronome ele tornaram mais evidente a diferença entre este e os pronomes eu e $t u$ : o primeiro flexiona-se em gênero e é derivado etimologicamente de uma única raiz: ille e flexões. No que diz respeito à primeira pessoa tem-se três raízes que deram origem ao eu, me e ao plural nós.

A Segunda pessoa formou-se a partir de duas: tu e vós. Diferentemente, de um único demonstrativo formaram-se todas as flexões de $3^{\underline{a}}$ pessoa. Com um "agravante" em favor da forma 
nominativa: ele tanto serve de nominativo quanto de forma oblíqua preposicionada enquanto que mim e $t i$ (diferentes de $e u$ e $t u$ ) são as formas preposicionadas das outras duas pessoas.

Esta aproximação morfológica com os nomes e os demonstrativos (flexionam em gênero e número: ele, ela, eles, elas) e a aproximação semântica (refere-se a um substantivo) parece ter colaborado para uma aproximação sintática com os mesmos na língua falada: a não distinção de casos. ("Diz-se, portanto, ele anda, falo a ele, vejo ele, exatamente como Pedro anda, falo a Pedro e vejo Pedro." (Mattoso Câmara, 1972:49)).

\subsection{Divergências entre o pronome ele e os pronomes eu e tu}

Esses aspectos levantados com relação à origem e evolução do ille latino para o ele português, pertinentes à questão formulada na página 221 (parágrafo 2): O que leva o pronome ele a se comportar diferentemente dos outros dois da sua classe? podem ser sumarizados da forma que se segue:

\section{A) No aspecto semântico}

- O pronome ele não pode ser considerado como pessoa gramatical. O conceito de pessoa gramatical está vinculado à participação do ente ao qual o pronome se refere, como ator, no processo comunicativo. Este é constituído pelos pronomes eu-falante - e $t u$-ouvinte.

- Os pronomes de $1^{\mathrm{a}}$ e $2^{\mathrm{a}}$ pessoa só podem ser associados a gênero animado, pois só se referem a pessoas, jamais a coisas, enquanto o pronome de $3^{a}$ pessoa é o único apto a expressar o inanimado.

- A origem do pronome ele é o pronome demonstrativo latino ille. Como todo demonstrativo, o ille tinha a capacidade de referência exofórica e endofórica. Por causa dessa dupla possibilidade referencial e do seu duplo emprego, adjetivo ou substantivo, revelou-se muito produtivo na passagem do latim às línguas românicas. Ainda no latim o pronome ille expande seu campo de 
atuação podendo substituir o anafórico is e o pronome de identidade ipse. No português o pronome aquele é exemplo da conservação da quase totalidade das características do ille; o artigo definido provém do emprego específico do illu-como adjetivo e o pronome pessoal de terceira posição ele é resultado do emprego substantivo do ille, exercendo a referência intra-textual. O pronome português ele herdou ambas as capacidades do demonstrativo latino e especializou-se, como substantivo, na referência textual, que é derivada da situacional: referência primária do demonstrativo latino ille, de natureza adjetiva. A forma nominativa ele < ille parece ser a que, mais freqüentemente e de modo mais transparente, exerce essas duas capacidades. As formas oblíquas correspondentes $o<i l l u$ - (acusativo) e lhe $<$ illi (dativo) são empregadas endoforicamente.

- Além das distinções internas com relação à maior capacidade do ele de expressar as duas referências, há a distinção entre as pessoas (a $1^{\mathrm{a}}$ e $2^{\mathrm{a}}$ pessoa de um lado, e a $3^{\mathrm{a}}$ do outro) no que se refere à capacidade referencial típica de cada uma. Segundo Halliday e Hasan (op. cit., p.48) as formas de primeira e segunda pessoas essencialmente se referem à situação, ao passo que as da terceira pessoa essencialmente se referem anafórica e cataforicamente ao texto. Mattoso Câmara assim sintetiza essa distinção: "o pronome ele e flexões está ligado aos nomes, dos quais é um substituto; ao contrário, os pronomes da primeira e segunda pessoa não se referem a um nome, mas diretamente às pessoas do discurso.”

\section{B) No aspecto sintático}

O pronome ille era de natureza adjetiva e, neste emprego, exercia a dêixis extra-textual. O seu emprego substantivo pode ser associado à sua capacidade de referência endofórica. O pronome ele do português originou-se desse último emprego do ille e continua empregado substantivamente nesta língua. Funciona como núcleo do sintagma e pode assumir diversas funções sintáticas: sujeito e complemento preposicionado ou não. Pode, dessa forma, 
ser regente ou regido, diferentemente do clítico o que se emprega apenas como complemento direto.

\section{C) No aspecto morfológico}

- O pronome ele apresenta uma forma livre e tônica, variável em gênero e número pelo modelo dos nomes (ele, ela, eles, elas) e duas formas clíticas adverbiais, que conservam a oposição latina entre acusativo e dativo. A primeira flexiona-se também em gênero e número ( $o, a, o s, a s)$ e a última somente em número (lhe, lhes). Os outros dois pronomes eu e tu (plural nós e vós) apresentam formas supletivas que conservam a oposição latina entre acusativo, dativo e formas preposicionadas. Essas variam apenas em número.

- Um segundo aspecto da morfologia do pronome ele e flexões, que o distancia dos outros pronomes pessoais, é o fato de ele se originar de uma única raiz: ille e flexões. Os pronomes precedentes $e u$ e $t u$ lançaram mão, no processo de formação do quadro pessoal, de formas supletivas. A primeira pessoa é composta de três raízes: eu, me e nós. A segunda formou-se a partir de duas: tu e vós.

- Essa formação de raiz única para o pronome ele e flexões e de raízes diferentes para as outras pessoas do quadro pessoal permite ao primeiro a coincidência da forma ele tanto para sujeito quanto para objeto preposicionado. Ao contrário, a primeira e a segunda pessoa apresentam formas distintas para sujeito e objeto preposicionado: $\mathrm{eu}$ : $\mathrm{mim}$; $\mathrm{tu}$ : $\mathrm{ti}$.

\section{Palavras finais}

O estudo acima teve a intenção de mostrar, contrariamente ao que foi sugerido por Mattoso Câmara (1972), que o português arcaico e o brasileiro contemporâneo possuem um subsistema próprio, composto dos pronomes de $3^{\underline{a}}$ posição, em que todas as funções sintáticas estão representadas pela mesma forma: ele (ela, 
eles, elas). A justificativa para a independência do pronome ele explica-se pela origem demonstrativa do mesmo. A volta ao latim, através da análise do seu sistema pronominal, e o acompanhamento da evolução do pronome latino ille ao ele português tornaram evidentes a verdadeira identidade do ele e seu emprego no português do Brasil.

Esperamos com este artigo, que dá continuidade ao trabalho de dissertação, preencher diversas lacunas deixadas por trabalhos que trataram do assunto mas não aprofundaram devidamente a questão. Também, com este estudo diacrônico, lançar novas luzes à questão polêmica do aspecto histórico do fenômeno: arcaísmo ou brasileirismo.

Para os partidários do 'brasileirismo' esclarecer que hipóteses do tipo "falsa analogia a partir do emprego sujeito diante de um infinitivo complemento de um outro verbo" 15 e "conseqüência do desaparecimento da preposição $a$ do dativo enfático"16 não explicam, na verdade, a origem do fenômeno. São apenas explicações superficiais a partir de observações de algumas estruturas esparsas da língua.

Para os partidários do 'arcaísmo' esperamos ter contribuído, a partir dos dados arcaicos novos e mais próximos dos da língua brasileira contemporânea, para fortalecer as suas posições.

Com a escolha dos dados arcaicos a partir da documentação notarial esperamos não só alertar os estudiosos de lingüística histórica para o valor desse tipo de texto, para a pesquisa, mas também contrapô-los aos dados apresentados até então para esse período.

E por fim esperamos ter deixado claro que a nossa pesquisa tem como objeto de estudo o pronome ele e flexões encaixado no sistema pronominal pessoal. E, como tal, realçou as divergências internas - resistência em se flexionar em caso - e externas - não integração morfológica e semântica - que esse pronome apresenta

${ }^{15}$ MARROQUIM, 1934. p.176

${ }^{16}$ PAIVA BOLÉO, 1934. p.33-34 
no sistema, provenientes de sua origem demonstrativa. Constatouse ainda que, em ambos os períodos estudados, o ele ocorre não só como objeto direto mas tem grande facilidade em aparecer em todas as outras funções sintáticas. O fenômeno configurou-se, então, como uma retenção sintática através do tempo.

\section{Referências Bibliográficas}

BYNON, Theodora. Sintatic Reconstruction: a case study In: Proceeding of the XIII International Congress of Linguists. Tokyo: Hattore, 1985.

BYNON, Theodora. Historical Linguistics. Cambridge: Cambridge Textbooks in Linguistics, 1993.

CASTILHO, Ataliba Teixeira de (Org.). Português Culto Falado no Brasil. Campinas: UNICAMP, 1989.

CYRINO, Sônia Maria Lazzarini. Observações sobre a mudança diacrônica no português do Brasil: objetos nulos e clíticos. In: Ian Roberts e Mary Kato. Português Brasileiro: Uma Viagem Diacrônica, homenagem a Fernando Tarallo. Campinas: UNICAMP, 1993. Capítulo V, p.163-184.

DECAT, Maria Beatriz Nascimento. Construções de Tópico em Português:

Uma Abordagem Diacrônica à luz do encaixamento no sistema pronominal. In: Fernando Tarallo (org.). Fotografias Sociolinguísticas. Campinas: Pontes, 1989. Capítulo 7, p.113-139.

GALVES, Charlotte. A Sintaxe do Português Brasileiro. In: Marco Antônio de Oliveira \& M. Nascimento (Orgs.). Ensaios de Lingüística. Cadernos de Lingüística e Teoria da Literatura da FALE, Belo Horizonte, UFMG, n.13, 1987.

HALLIDAY, M. A K., HASAN, Ruqaiya. Cohesion in English. New York: Longman, 1976.

LAUSBERG, Heinrich. Lingüística Românica. Lisboa: Fundação Calouste Gulbenkian, 1974. 
LEAL, Mํ. A. Fonseca. Complementos Preposicionados no Sintagma Verbal Português: uma abordagem Sincrônica e Diacrônica. In : Mari e Leal. Reflexões Diacrônicas. Belo Horizonte: FALE/UFMG, 1992.

MAIA, Clarinda de Azevedo. História do Galego-Português. Estado Lin-güistico da Galiza e do Noroeste de Portugal desde o século XIII ao século XV (com referência ao Galego moderno). Coimbra: INIC, 1986.

MARROQUiM, Mário. A língua do Nordeste. São Paulo: Cia. Editora Nacional, 1934. p.176

MATTOSO CÂMARA JR., J. Dispersos de J. Mattoso Câmara Jr. Rio de Janeiro: Fundação Getúlio Vargas, 1972.

NUNES, Jairo M. Direção de Cliticização, Objeto Nulo e Pronome Tônico na Posição de Objeto em Português Brasileiro. In: Ian Roberts e Mary Kato (orgs.). Português Brasileiro; Uma viagem diacrônica: homenagem a Fernando Tarallo. Campinas: Editora da Unicamp, 1993. Capítulo: VII, p.207-222.

OMENA, Nelize Pires de. Pronome Pessoal de Terceira Pessoa. Suas Formas Variantes em Função Acusativa. Dissertação de Mestrado, PUC, Rio de Janeiro, 1978.

PAIVA BOLÉO, Manuel. Brasileirismos. Coimbra: Coimbra editora, 1943. p.33-34.

SEABRA, M. C. Costa. Uma Abordagem Diacrônica da Construção de Tópico em Português. Belo Horizonte: Faculdade de Letras da UFMG, 1994. (dissertação de mestrado inédita em lingüística).

Os dados apresentados foram extraídos dos seguintes textos

AZEVEDO, Pedro de. Nova Leitura da Notícia de Torto (texto do séc. XIII). Revista Lusitana, Lisboa, vol. XVII, p.203-206, 1914. ASSIS CINTRA. Os clássicos e o Antigo Vernáculo. Rio de Janeiro: A Grande Livraria Leite Ribeiro, 1921. 
MAIA, Clarinda de Azevedo. História do Galego - Português; Estado Lingüístico da Galiza e do Noroeste de Portugal desde o século XIII ao século XVI (com referência à situação do galego moderno). Coimbra: INIC, 1986.

MARTINS, Ana Maria. Clíticos na História do Português. Lisboa: Faculdade de Letras, Universidade de Lisboa, 1994 (Dissertação de Doutoramento em Lingüística Portuguesa). "Apêndice Documental". PRADO, Adélia. Cacos para um Vitral. Rio de Janeiro: Nova Fronteira, 1980.

PRADO, Adélia. et al. Contos Mineiros. São Paulo: Ática, 1984.

PRADO, Adélia. História de uma Dona Doida de Pedra. Jornal $O$ Tempo. Belo Horizonte, 21 nov. 1997. Especial 1 ano, p.11.

SIVEIRA BUENO, Francisco da. Estudos de Filologia Portuguesa. 2.ed. São Paulo: Saraiva, 1954. $1^{\circ}$ vol. p.285

ZURARA, Gomes Eanes de. Prosas Históricas. Seleção, prefácio e notas de Rodrigues Lapa. Coleção "Textos Literários". Belo Horizonte: Itatiaia, 1960. p.37 


\section{Resumo}

A língua evolui com o passar dos tempos devido a diversos fatores que podem ser externos ou internos a ela. No âmbito das evoluções internas verificamos fenômenos de mudanças e também de conservações lingüísticas. Este artigo analisa um fato lingüístico de retenção: o fenômeno do emprego do pronome tônico de $3^{a}$ pessoa em função objetiva direta, doravante 'ele acusativo', no português brasileiro sob uma perspectiva diacrônica. Partindo do princípio de que o fenômeno é tão antigo quanto a própria língua portuguesa e que representa um caso de retenção sintática, fez-se necessário um recuo até o período arcaico. A explicação para a presença do ele acusativo em ambos os períodos (arcaico e contemporâneo) foi buscada na sua origem latina.

\section{Abstract}

As time goes by language changes dues to several factors, which may be external or internal to it. Within internal evolution, we can verify phenomena of linguistic change, as well as linguistic retention. This paper analyses a case of retention: the use of $3 \mathrm{rd}$. Person stressed pronoun, in direct object function henceforth 'ele acusativo' in Brazilian Portuguese, following a diachronic perspective. Taking from the principle that this use exists ever since the Portuguese language itself does and that it represents a case of sintatic retention, it was necessary to go back to the archaic period ( of the Portuguese language). The explanation to the presence of 'ele acusativo' in both periods (archaic and contemporary) was searched in its Latin origin. 